\title{
Anemia and its impact on dysmenorrhea and age at menarche.
}

\author{
Dr. Rafia Bano \\ Assistant professor, Department of Clinical Nutrition, College of Applied Medical Sciences, University of Hail, \\ KSA
}

\begin{abstract}
Introduction: Dysmenorrhea, or painful menstrual period, is a common complaint among 50\% adolescent girls. Therefore, a cross sectional study on Urban adolescent secondary school girls aged (10 - 15 years) was conducted with an objective to know the prevalence of anemia and its impact on the age at menarche, dysmenorrhea and total iron intake in the diet.

Methodology: Seven hundred girls were selected from four different schools of Aligarh city by Stratified Random Sampling. Questionnaire was prepared after piloting on a small sample of population and was modified accordingly to determine the number of menarcheal subjects and age at menarche Prevalence and extent of dysmenorrhea was also looked for. Mean, S.D, Chi square and linear regression analysis was done through spss 16.0 software for the purpose of statistical analysis (Dixit, 2003).

Results and discussion: Out of 700 subjects, 400 girls had reached their menarche. The mean age at menarche was calculated to be 12.36 years. Among these 400 post menarcheal girls it was found that 135 (33.7\%) girls suffered from different degrees of anemia. Analysis of the results revealed that the age at menarche was significantly correlated with anemia. Results also concluded that a significantly high correlation was found between severity of dysmenorrhea and anemia prevalence. The prevalence of anemia was also significantly correlated with the dietary intake of iron. The percentage of girls experiencing anemia decreased with increasing iron intake in the diet. Correlation between the various degrees of dysmenorrhea and iron intakes was also found to be fairly significant.

Conclusion: From the above mentioned results it was concluded that anemia and dysmenorrhea are interrelated to each other and both are significantly affected by the iron intake of diet. Anemias as well as dysmenorrhea are the commonest health problems of adolescent girls. An improved understanding of the physiology will greatly help nutritionists and health workers to build more effective treatment methodologies.
\end{abstract}

Key words: Adolescence, Anemia, Dysmenorrhea, Menarche

\section{Introduction:}

In adolescent age girls constitute a more vulnerable group, particularly in India where the female child is a neglected one and are exposed to greater risk of reproductive mortality and morbidity.

Nutritional deprivation, increased iron demands for adolescent growth, excessive menstrual losses all aggravate and exacerbate preexisting anemia and its ill effects (O.P.Ghai, 2003). Iron deficiency and anemia are important health problems irrespective of the age and socioeconomic status. Majority of the girls do not have the knowledge of their nutritional needs, especially increasing food intake to meet the demands of pubertal growth; and the basic facts related to their reproductive health.

Adolescents constitute 22.8\% of population in India as on 1st March 2000 (O.P.Ghai, 2003). According to United Nation's population fund, $21.9 \%$ of India's total population in 2001 belonged to the adolescent age group. According to world population prospects (2002), the population of adolescent females was $9.9 \%$ of the total population, with $5.1 \%$ in the age group $10-14$ years.

Normal menstrual cycles are often associated with difficult and painful menstruation known as dysmenorrhea. The term dysmenorrhea is derived from Greek words dys meaning difficult/painful/abnormal; meno meaning month; and rrhea meaning flow. Dysmenorrhea may be accompanied by nausea, vomiting, diarrhea, headache, irritability or anorexia. It is a common complaint in around $50 \%$ of post pubescent females (Karim and Popat, 2009). It may be primary or secondary depending on the cause.

A large number of girls remain ill infirmed about the basic facts related to their reproductive health. The main remedy could be the awareness about the various important factors which if implemented could solve the health problems to some extent.

\section{Objectives:}

1 - To find out the mean age at menarche.

2 - To establish the relationship between prevalence of iron deficiency anemia and age at menarche.

3 - To correlate the prevalence of dysmenorrhea with age at menarche and iron intake in the diet. 


\section{Methodology}

The present cross sectional study was undertaken in secondary school adolescent girls (10-15 yrs) from four different regions of Aligarh city. 700 girls were selected through stratified random sampling procedure. (Dixit J.V., 2003). Based on the age at menarche the sample was classified as early ( $9.6-11.5$ years), normal (11.5 - 13.6 years) and late (13.6 - 15 years) matures (Kaul, 2004; Nelson, 1994).

The study was carried out using a pre tested and modified questionnaire. All the girls were asked to fill the questionnaire personally in a regular class room. The questionnaire included questions regarding the subject's age, her age at menarche, severity of dysmenorrhea, medical attention and use of analgesics.

Identification data and age of the girls were ascertained from school records also. The age was rounded off to the nearest preceding year. Hence 11 years was referred to all those, 10.01 through 10.12 years with an approximate mean of 10.06 years. Age at menarche was noted in completed years and months.

A 24 hour dietary recall method was applied for the purpose of getting the per day iron intake in diet (Antia, F. P., 1989). Blood samples were collected for biochemical assessment of anemia in the presence of a medical practitioner; clinical examination of pallor was also done (Kumar, 2003). The colour of the mucus membrane particularly those on the underside of the eyelid, in which blood supply is close to the surface, provides an opportunity to observe the pigmentation of the blood. A pale mucous membrane is suggestive of anemia, whereas a more highly coloured membrane usually occurs in persons with adequate hemoglobin levels. Presence of any clinical signs of nutritional deficiencies especially iron deficiency anemia was specifically looked . Pallor of palms, conjuctiva, buccal cavity and nails were looked for (Ahmad, I, 2000) . Anemia was graded according to haemoglobin levels and pallor as mild, moderate, severe, and extremely severe.

The severity of menstrual pain was measured using the verbal multidimensional scoring system reported by Andersch and Milson (1982). This scoring system grades pain as none, mild, moderate, or severe and takes into account the effect of pain on daily activity, systemic symptoms, and analgesic requirements. Each woman was asked to report the date of the beginning of her last menses, the length of her usual menstrual cycle, and the number of days of bleeding.

Mean, S.D., $\chi 2$ test and linear regression analysis were done to assess the correlation between the selected variables, anemia and dysmenorrhea through SPSS 16.0 Software.

\section{Results}

The overall mean menarcheal age was found to be $12.36 \pm 1.16$ years (table I), which is comparable to various studies done on national and international level. Results of the study from table II revealed that among menarcheal subjects the number of anemic girls increased with increasing age from 2 (age 10 years) to 48 (age 15 years). Among 400 post menarcheal girls, a total of 135 (19.3\%) girls were found with various degrees of anemia.

Age at menarche was also found to be significantly correlated with anemia (table III).Among the early menarcheal population the no of girls with any of the degrees of anemia (24) was found lower than the number of girls with no anemia (79), while among the late matures there were only 23 menarcheal anemic girls. Results of the study concluded that there was a positive and significant correlation between anemia and severity of dysmenorrhea (table IV).

After analyzing the results it was revealed that prevalence of anemia was statistically correlated with the per day intake of iron (table V). Table VI clearly shows that severity of dysmenorhea was inversely correlated with iron intake in diet.

\section{Discussion}

Analysis of the results concluded that anemia was positively correlated with the age of menarcheal girls as according to some other studies (Anuradha Shekhar, 2003; Subita Basu, 2005). Table III revealed that among the early maturing population ( 9.6 - 11.5 years), the number of girls with either of the degrees of anemia (24) was found lower than the number of girls with no anemia (79). On the other hand the case was just reverse among the late matures (13.6 - 15 years). Prevalence of anemia and dymenorrhea were also found to be significantly correlated. It is quite evident from table IV that the number of girls experiencing anemia increased with increasing severity from $0-51$ in mild and $3-10$ in moderately anemic girls. Few studies (Rostami Maryam, 2007; Marjori Banks, 2006 and Anderson, 1998) to date showed any such correlations. There is lack of available literature especially from the developing countries like India. Alan D . Rogol and Pamela A . Clark, 2000 , also showed in their study that under nutrition and anemia delays age at menarche to as much as 1.5 - 2 years.

In a study by S. Aneja (1992), anemia was found as a common health problem irrespective of the socio economic status. Anemia was found in $20 \%$ urban girls in a study by D. S. Deo, 2004 . Sabita Basu, et al ., 2005, showed prevalence of anemia in Chandigarh as $23.9 \%$ in adolescent girls and was 
related to nutritional status. Another study by Anuradha Shekhar, 2005, showed prevalence of anemia as high as $54.6 \%$ and also showed higher mean menarcheal age .

Number of mild, moderately anemic girls decreased with increasing iron intake in diet, showing an inverse correlation. According to table V, there were $146(20.9 \%)$ mildly anemic girls in low iron intake $(<15 \mathrm{mg})$ as against only $11(1.6 \%)$ in adequate iron intake $(20-28 \mathrm{mg})$. Among the moderately anemic girls the number decreased from $46(6.6 \%)$ to $2(0.3 \%)$ from $<15 \mathrm{mg}$ to $20-28 \mathrm{mg}$ iron intakes respectively.

Table VI concludes that among the mild, moderate as well as severe degrees of dysmenorrhea, the number of girls decreased linearly with increasing iron intake. This aspect was a relatively new finding as no relevant literature was found to date showing any such correlations on dysmenorrhea and dietary iron intake.

\section{Conclusion}

An improved understanding of the physiology of dysmenorhea as well as anemia may result in building more effective treatment regimens (Rostami Maryam, 2007). The underlying cause of anemia should be looked for. Adolescence is a crucial phase especially for girls as they are entering the reproductive phase (Bansal and Mehra, 1998). Holistic approaches should be undertaken to meet the developmental as well as the nutritive needs to over come nutritional deficiencies and reproductive health problems (Ghai, 2003 ; Deo D.S.,2004). Social change should be promoted through the education of parents, family, community and the decision makers at the national and international levels.

\section{References:}

[1] Dixit, J.V.; Principles and practices of Bio-satiation; second edition; 2003

[2] Ghai, O.P.; Essential Pediatrics; Deptt. of Pediatrics, All India Institute of Med. Science, New Delhi 2003.

[3] Karim Anton Calis, and Vaishali Popat et al, Dysmenorrhea, Medscape's continually updated clinical References; updated Jan . $28 ; 2009$.

[4] Kaul et al; SES as a determinant of age at menarche, Indian Pediatrics, Journal of Indian Academy of Pediatrics, Volume 41, No. $1,2004$.

[5] Nelson, W.E.; Text book of Pediatrics 14th edition; W.B. Sunders Company, 1994.

[6] Antia F. P.; Clinical dietetics and nutrition, Oxford University Press; Revised edition, 1989

[7] Kumar, Vinod CS, Anand Kumar H, et al; Prevalence of anemia and worms infestation in school going girls at Gulbarga; Indian Pediatrics, Journal, volume 40; No. 1, Jan 2003.

[8] Ahmad I, Khan MR, Islam M, Kabir I, Fuchs G J; Anemia and iron deficiency among adolescent school girls Periurban Bangladesh; Euopean journal of Clin. Nutr; 54: 678-683, 2000.

[9] Shekhar, Anuradha; Iron status of adolescent girls and its effect on physical fitness. Indian Journal of Nutr. Dietetics, 42, 451, Oct. 2003.

[10] Basu, Subita; Srikanta Buring Ranjita hazarika and Viena Parmar; Prevalence of Anemia among school going adolescents of Chandigarh; Indian Pediatrics Volume 42; No 6 June, 2005.

[11] Rostami Maryam, The study of dysmenorrhoea in High School girls: Pakistan Journal of Medical Sciences; October - December 2007; Vol. 23, No. 6. 928-931.

[12] Marjori Banks A., And Proctor M.L. et al; Dysmenorrhea BMJ. 2006; 332: 1134-1138 (13 May).

[13] Anderson M., An epidemiological study of young women with dysmenorrhoea; Am Journal of Gynecology, $1998 ; 6$ (15) 655 -0.

[14] Alan D. Rogol and Pamela A. Clark; BMI and Iron deficiency anemia; American Journal of Community Nutrition, volume 72, No. 2,2000 .

[15] S. Aneja and Kapoor T.; Health profile of adolescent girls, Indian Journal of Community medicine, vol.24, NO. 9, 1992.

[16] Deo, D.S.; and Chattargi, C.H.; Health profile of adolescent school girls - A comparative study; Indian Medical Gazette, No. 1, Volume CXXXVIII, Jan 2004.

[17] Bansal, R.D. and Mehra, M; Adolescent girls: an emerging priority; Indian Journal of public health; volume 42; No 1 : 1998

Table I- Distribution of mean age at menarche according to age

\begin{tabular}{|l|l|l|l|}
\hline Age & No. of girls & $\begin{array}{l}\text { Mean age at } \\
\text { menarche (yrs) }\end{array}$ & S.D. \\
\hline 10 & 8 & 9.9 & 0.31 \\
11 & 33 & 10.7 & 0.35 \\
12 & 58 & 11.5 & 0.66 \\
13 & 89 & 12.3 & 0.58 \\
14 & 99 & 12.7 & 0.97 \\
15 & 113 & 13.3 & 0.94 \\
\hline Total Menarcheal & 400 & 12.36 & 1.16 \\
\hline Total & & & \\
Non-menarcheal & 300 & - & - \\
\hline
\end{tabular}


Table II-Correlation of anemia prevalence and age of menarcheal subjects

\begin{tabular}{|c|c|c|c|c|c|}
\hline \multirow[t]{2}{*}{ Age } & \multirow[t]{2}{*}{ No. of girls } & \multicolumn{4}{|l|}{ Anemia } \\
\hline & & Absent & $\%$ & Present & $\%$ \\
\hline 10 & 8 & 6 & 1.5 & 2 & 0.5 \\
\hline 11 & 33 & 26 & 6.5 & 7 & 1.75 \\
\hline 12 & 58 & 45 & 11.2 & 13 & 3.2 \\
\hline 13 & 89 & 63 & 15.7 & 26 & 6.5 \\
\hline 14 & 99 & 60 & 15.0 & 39 & 9.75 \\
\hline 15 & 113 & 65 & 16.2 & 48 & 12.0 \\
\hline Total & 400 & 265 & 66.3 & 135 & 33.7 \\
\hline
\end{tabular}

$\chi 2=31.6$ at df $10, \mathrm{P}<0.01$

Table III - Correlation of Anemia prevalence and age at menarche

\begin{tabular}{|l|l|l|l|l|l|l|l|l|}
\hline \multirow{2}{*}{ Age at menarche } & \multicolumn{4}{|l|}{ Anemia present / absent } & Total & $\%$ \\
\cline { 2 - 8 } & Absent & $\%$ & + mild & $\%$ & ++ moderate & $\%$ & & \\
\hline $9.6-11.5$ & 79 & 76.6 & 22 & 21.3 & 2 & 1.94 & 103 & 100 \\
$11.6-13.5$ & 163 & 69.3 & 58 & 24.7 & 14 & 0.43 & 235 & 100 \\
$13.6-15$ & 23 & 37.1 & 35 & 56.4 & 4 & 6.45 & 62 & 100 \\
\hline Total & 265 & 66.3 & 115 & 28.7 & 20 & 5.0 & 400 & 100 \\
\hline
\end{tabular}

$\chi 2=32.47$ df $4 ; \mathrm{P}<0.01$

Table IV - Severity of dysmenorrhea according to anemia prevalence

\begin{tabular}{|l|l|l|l|l|}
\hline \multirow{4}{*}{ Dysmenorrhea } & Anemia present / absent & Total \\
\cline { 2 - 4 } & Absent & + mild & ++ moderate & \\
\hline Absent & 12 & 0 & 3 & 15 \\
Mild & 52 & 25 & 3 & 80 \\
Moderate & 119 & 39 & 4 & 162 \\
Severe & 82 & 51 & 10 & 143 \\
\hline Total & 265 & 115 & 20 & 400 \\
\hline
\end{tabular}

$\chi 2=21.7$ df $6 ; \mathrm{P}<0.01$

Table V - Anemia prevalence according to dietary iron intake

\begin{tabular}{|l|l|l|l|l|l|l|l|l|}
\hline \multirow{2}{*}{ Iron intake } & \multicolumn{4}{|l|}{ Anemia present / absent } & Total & $\%$ \\
\cline { 2 - 8 } & Absent & $\%$ & + mild & $\%$ & ++ moderate & $\%$ & & \\
\hline$>15$ & 210 & 30 & 146 & 20.9 & 46 & 6.6 & 402 & 57 \\
$15-19$ & 147 & 21 & 66 & 9.4 & 29 & 4.1 & 242 & 34.6 \\
$20-28$ & 43 & 6.1 & 11 & 1.6 & 2 & 0.3 & 56 & 8.0 \\
\hline Total & 400 & 57.1 & 223 & 31.9 & 77 & 11.0 & 700 & 100 \\
\hline
\end{tabular}

$\chi 2=15.8$ df $4 ; \mathrm{P}<0.05$

Table VI - Correlation between severity of dysmenorrhea and dietary iron intake

\begin{tabular}{|l|l|l|l|l|l|}
\hline \multirow{2}{*}{ Iron intake } & Dysmenorrhea & Mild & Moderate & Severe & \\
\cline { 2 - 5 } & Absent & 91 & 39 & 13 & 221 \\
$15-19$ & 78 & 57 & 31 & 1 & 149 \\
$20-28$ & 60 & 14 & 10 & 1 & 30 \\
\hline Total & 5 & 162 & 80 & 15 & 400 \\
\hline
\end{tabular}

$\chi 2=14.1$ df $6 ; \mathrm{P}<0.05$ 